\title{
Genetic architecture of quantitative trait loci associated with morphological and agronomic trait differences in a wild by cultivated barley cross
}

\author{
L. Gyenis, S.J. Yun, K.P. Smith, B.J. Steffenson, E. Bossolini, M.C. Sanguineti, and \\ G.J. Muehlbauer
}

\begin{abstract}
Hordeum vulgare subsp. spontaneum is the progenitor of cultivated barley (Hordeum vulgare L.). Domestication combined with plant breeding has led to the morphological and agronomic characteristics of modern barley cultivars. The objective of this study was to map the genetic factors that morphologically and agronomically differentiate wild barley from modern barley cultivars. To address this objective, we identified quantitative trait loci (QTLs) associated with plant height, flag leaf width, spike length, spike width, glume length in relation to seed length, awn length, fragility of ear rachis, endosperm width and groove depth, heading date, flag leaf length, number of tillers per plant, and kernel color in a Harrington/OUH602 advanced backcross $\left(\mathrm{BC}_{2} \mathrm{~F}_{8}\right)$ population. This population was genotyped with 113 simple sequence repeat markers. Thirty QTLs were identified, of which 16 were newly identified in this study. One to 4 QTLs were identified for each of the traits except glume length, for which no QTL was detected. The portion of phenotypic variation accounted for by individual QTLs ranged from about $9 \%$ to 54\%. For traits with more than one QTL, the phenotypic variation explained ranged from $25 \%$ to $71 \%$. Taken together, our results reveal the genetic architecture of morphological and agronomic traits that differentiate wild from cultivated barley.
\end{abstract}

Key words: barley, Hordeum vulgare L., Hordeum vulgare subsp. spontaneum, advanced backcross, quantitative trait locus.

Résumé : L'Hordeum vulgare subsp. spontaneum est l'ancêtre de l'orge cultivée (Hordeum vulgare L.). La domestication et la sélection ont mené aux caractères morphologiques et agronomiques des cultivars modernes d'orge. L'objectif de cette étude était de cartographier les facteurs génétiques qui distinguent l'orge sauvage de l'orge cultivée moderne sur les plans morphologique et agronomique. Pour atteindre ce but, les auteurs ont identifié des QTL associés à la hauteur, la largeur de la feuille étendard, la longueur et la largeur de l'épi, la longueur des glumes par rapport à la longueur des graines, la longueur des barbes, la fragilité du rachis, la largeur de l'albumen, la profondeur du sillon, la date d'épiaison, la longueur de la feuille étendard, le nombre de thalles par plant et la couleur des grains dans une population $\mathrm{BC}_{2} \mathrm{~F}_{8}$ issue du croisement Harrington/OUH602. La population a été génotypée avec 113 marqueurs SSR. Trente QTL ont été identifiés dont 16 étaient inédits. D'un à quatre QTL ont été identifiés pour chacun des caractères à l'exception de la longueur des glumes pour lequel aucun QTL n'a été détecté. La part de la variation phénotypique expliquée par les QTL individuels variait entre $9 \%$ et $54 \%$. Pour les caractères ayant plus d'un QTL, la variation phénotypique expliquée variait entre $25 \%$ et $71 \%$. Ensemble, ces résultats révèlent l'architecture génétique des caractères morphologiques et agronomiques qui distinguent les orges sauvage et cultivée.

Mots-clés : orge, Hordeum vulgare L., Hordeum vulgare subsp. spontaneum, rétrocroisement avancé, caractère quantitatif.

[Traduit par la Rédaction]

Received 19 February 2007. Accepted 8 July 2007. Published on the NRC Research Press Web site at genome.nrc.ca on 15 August 2007. Corresponding Editor: D. Somers.

L. Gyenis, ${ }^{1}$ K.P. Smith, and G.J. Muehlbauer. ${ }^{2}$ Department of Agronomy and Plant Genetics, 411 Borlaug Hall, University of Minnesota, St. Paul, MN 55108, USA.

S.J. Yun. ${ }^{1}$ Division of Biological Resources Sciences, Chonbuk National University, Jeonju 561-756, Korea.

B.J. Steffenson. Department of Plant Pathology, University of Minnesota, St. Paul, MN 55108, USA.

E. Bossolini and M.C. Sanguineti. Department of Agroenvironmental Sciences and Technology, University of Bologna, Viale Fanin 44, 40137 Bologna, Italy.

${ }^{1}$ These authors contributed equally to this work.

${ }^{2}$ Corresponding author (email: muehl003@umn.edu). 


\section{Introduction}

Barley (Hordeum vulgare L.) is thought to have originated from $H$. vulgare L. subsp. spontaneum (C. Koch) Thell. $(H s p)$ in the Fertile Crescent, where diverse populations of Hsp are still present (Nevo 1992). Domestication and breeding led to the development of modern barley cultivars. Comparative analysis of morphological and agronomic traits in cultivated barley and $H s p$ revealed 10 characteristics that distinguish cultivated from wild barley (Badr et al. 2000). These characteristics are plant height, flag leaf width, spike length, spike width, glume length in relation to kernel length, awn length, number of ear rows, fragility of ear rachis, endosperm width, and groove depth. Therefore, the wild barley progenitor is a useful source for genetic analysis of morphological and agronomic traits differing between wild and cultivated barley.

Quantitative trait locus (QTL) mapping is a powerful approach for locating genomic regions controlling complex traits. Advanced backcross QTL (AB-QTL) analysis was developed as an approach to examine alleles from unadapted genotypes in an adapted genetic background (Eshed and Zamir 1995; Tanksley and Nelson 1996). AB-QTL analysis is based on developing backcross populations of unadapted by adapted crosses and then conducting QTL analysis. This approach has been used extensively in a variety of plants including barley, rice, and tomato (e.g., Xiao et al. 1996; Fulton et al. 2000; Pillen et al. 2004; Talamè et al. 2004; von Korff et al. 2004; Li et al. 2005, 2006).

QTLs controlling a variety of morphological and agronomic traits in barley have been mapped. QTLs explaining plant height (Hayes et al. 1993; Tinker et al. 1996; Qi et al. 1998; Borem et al. 1999; de la Peña et al. 1999; Zhu et al. 1999; MarquezCedillo et al. 2001; Baum et al. 2003; Li et al. 2006), brittleness of rachis (Kandemir et al. 2000, 2004; Komatsuda et al. 2004; von Korff et al. 2006), spike length (Kjaer et al. 1995; Li et al. 2006), heading date (Hayes et al. 1993; Backes et al. 1995; Kjaer et al. 1995; Tinker et al. 1996; Powell et al. 1997; Qi et al. 1998; de la Peña et al. 1999; Marquez-Cedillo et al. 2001; Mesfin et al. 2003; von Korff et al. 2004), and tiller number (Baum et al. 2003) have been identified. Loci controlling kernel color have also been identified (Franckowiak 1997). Hori et al. (2005) used advanced backcross and doubled haploid populations derived from the Hsp accession H602 (OUH602) and cultivated barley, H. vulgare 'Haruna Nijo', to map QTLs for a variety of morphological and agronomic traits, but no QTL locations for glume length, groove depth, endosperm width, spike width, awn length, flag leaf width, and flag leaf length were reported. Furthermore, most of the previously identified QTLs were found in mapping populations that did not include wild barley. Thus, the genetic architecture of the morphological and agronomic differences between wild and cultivated barley is largely unknown. Our objectives in this study were to map the genetic factors underlying the morphological and agronomic characteristics differentiating cultivated and wild barley.

\section{Materials and methods}

\section{Plant materials}

An advanced backcross $(\mathrm{AB}) \mathrm{BC}_{2} \mathrm{~F}_{8}$ population was de- veloped from a cross between the Hsp accession OUH602 (OSU1, provided by P. Hayes, Oregon State University) and the 2-rowed standard malting cultivar $H$. vulgare 'Harrington' as described by Yun et al. (2006). This population was referred to as OUH602/Harrington $\mathrm{BC}_{2} \mathrm{~F}_{8}$ in a previous paper (Yun et al. 2006) but is referred to as Harrington/ OUH602 $\mathrm{BC}_{2} \mathrm{~F}_{8}$ in this paper. The $H s p$ accession is from the Fertile Crescent of the Middle East but its exact geographic origin is not known (Sato and Takeda 1997). Harrington was used as the female and OUH602 as the male to obtain the $\mathrm{F}_{1}$ plants. For the $\mathrm{BC}_{1}$ and $\mathrm{BC}_{2}$ generations, Harrington was used as the male. Ninety-eight random $\mathrm{BC}_{1}$ plants were backcrossed with Harrington to generate 98 $\mathrm{BC}_{2}$ plants, $1 \mathrm{BC}_{2} \mathrm{~F}_{1}$ tracing back to $1 \mathrm{BC}_{1} \mathrm{~F}_{1}$. Single-seed descent was used to advance progeny from the $\mathrm{BC}_{2} \mathrm{~F}_{1}$ generation to the $\mathrm{BC}_{2} \mathrm{~F}_{6}$ generation. Seed for trait evaluation was bulk-harvested from $\mathrm{BC}_{2} \mathrm{~F}_{7}$ plants derived from each $\mathrm{BC}_{2} \mathrm{~F}_{6}$ plant.

\section{DNA isolation and marker analysis}

DNA was isolated from leaf tissue of a single plant from each of $98 \mathrm{AB}$ lines $\left(\mathrm{BC}_{2} \mathrm{~F}_{6}\right)$. DNA isolation and simple sequence repeat (SSR) marker analysis were conducted according to Yun et al. (2005). A total of 113 SSR markers polymorphic for OUH602 and Harrington were evaluated in the AB population (Yun et al. 2006).

\section{Experimental design}

The morphological and agronomic trait data were obtained from 5 different environments. Field experiments were conducted in St. Paul, Minnesota, in 2001 (F01SP), 2002 (F02SP), and 2003 (F03SP) and in Cadriano, Italy, in 2002 (F02IT). A greenhouse trial was conducted in St. Paul in the winter of 2003 (G03SP). A randomized complete block design was used for each evaluation. Two replicates of each line were planted in the field evaluations in St. Paul and 3 replicates were used in the St. Paul greenhouse and the Cadriano field trials. Each replicate contained the 98 $\mathrm{AB}$ lines and the parents.

The soil type in the St. Paul field trials was Waukegan series with moderate permeability in the upper part and rapid permeability in the underlying material. Seed $(2 \mathrm{~g})$ of each AB line was planted in $120 \mathrm{~cm}$ rows with $60 \mathrm{~cm}$ of row spacing between lines.

The field trial in Cadriano was conducted on an Udic Ustochrept (fine silty, mixed, and mesic) soil. For each line, approximately $3 \mathrm{~g}$ of seed was planted in 2-row (2 $\mathrm{m} \mathrm{long}$ ) plots. The distance between rows within plots and between plots was 30 and $70 \mathrm{~cm}$, respectively. The seed was planted in the fall and overwintered in the field.

In the greenhouse, 4 seeds from each $A B$ line were planted in $13 \mathrm{~cm} \times 13 \mathrm{~cm}$ plastic pots filled with Metro Mix 200 growing media (Scotts-Sierra Horticulture Products Company, 14111 Scottslawn Road, Marysville, OH 43041, USA). After planting, all pots were watered and then moved to $4{ }^{\circ} \mathrm{C}$ for 7 days to break seed dormancy. After the cold treatment, the pots were placed in a greenhouse at $22{ }^{\circ} \mathrm{C}$ and $16 \mathrm{~h}$ daylight. Once the seeds had germinated, the plants were thinned to 2 plants per pot. 


\section{Morphological and agronomic traits}

Plant height, flag leaf width, spike length, spike width, glume length in relation to seed length, awn length, fragility of ear rachis, endosperm width, and groove depth were evaluated as described by Badr et al. (2000). Plant height was measured at the spike insertion (spike length measured individually) from the ground in 4 environments (F02IT, F02SP, F03SP, and G03SP). Flag leaf width was measured at the widest point of the flag leaf in F02SP, F03SP, and G03SP. Spike length was measured in F02IT, F02SP, F03SP, and G03SP and spike width was measured in F02SP, F03SP, and G03SP. Glume length compared with kernel length was measured as $1=$ longer, $2=$ equal, and $3=$ shorter in F03SP and G03SP. Awn length was measured in F02IT, F02SP, F03SP, and G03SP. Fragility of ear rachis was evaluated in F02IT by the presence of the rachis on the seeds after threshing, using a scale of 0 (no rachis) to 5 (rachis remained on all seeds). The characterization of ear rachis fragility in F03SP was changed to eliminate the labor-intensive seed-threshing process. Instead of threshing, we evaluated barley spikes in the field by gently touching the ripened heads of each line and scoring them as 1 (non-shattering Harrington type) or 2 (Hsp-type spikes fell apart from a gentle touch). Endosperm width and depth of the lateral seed grooves $(1=H s p$ type, $2-4=$ intermediate, $5=H$. vulgare type) were evaluated on seed from the F01SP and F03SP trials. Each seed was cut at the widest point with a razor blade and evaluated under a dissecting microscope. Heading date was measured as days after planting in St. Paul and the greenhouse environment and as days after 1 January 2002 in Italy. Heading date was noted in 4 environments (F02IT, F02SP, F03SP, and G03SP) and flag leaf length in three (F02IT, F03SP, and G03SP). The number of tillers per plant at the time of heading date assessment was measured in F02IT, F03SP, and G03SP. Kernel color was assessed based on a scale of 1 = light, 2 = gray, and $3=$ dark in F01SP and F03SP.

\section{Statistical analysis}

To determine the variation among environments, we used the PROC GLM procedure of SAS version 8.02 (SAS Institute Inc., Cary, North Carolina). For QTL identification, the single marker analysis method in Windows QTL Cartographer version 2.5 was utilized (Wang et al. 2005), considering a logarithmic odds (LOD) score of 2.3 and higher as significant. For traits with multiple QTL locations, the multiple regression model was used to determine the explained phenotypic variation.

\section{Results}

\section{Genetic mapping}

The Harrington/OUH602 AB population was previously genotyped with 111 SSR markers that span the barley genome (Yun et al. 2006). Two additional markers, Bmac0209 and Bmag0318a, were also used here to genotype the population. The SSR markers, except Bmac0209 and Bmag0318a, were previously mapped in the OUH602/Harrington recombinant inbred line (RIL) population (Yun et al. 2005). Thus, the genetic locations of the SSR markers in the AB population were inferred using the OUH602/Harrington
RIL population. The map location of Bmac0209 is $2.7 \mathrm{cM}$ from EBmac0558.2 on chromosome $3(3 \mathrm{H})$ at $46.8 \mathrm{cM}$, and Bmag0318a is $3 \mathrm{cM}$ from Bmac0209. The 113 markers grouped into 11 linkage groups, generating a total map length of $948 \mathrm{cM}$ (Yun et al. 2005). These 113 markers were used in the single-marker analysis for QTL detection.

\section{Phenotypic data}

Phenotypes of the AB lines and the 2 parents were evaluated for the 13 morphological traits at 2 to 4 environments. The phenotypic data are summarized in Table 1. All traits exhibited significant variation between lines $(p<0.0001)$. However, each trait (except seed color) exhibited significant $(p<0.05)$ genotype $\times$ environment interactions. Thus, the trait data from each environment were analyzed separately.

The relative phenotypic values of the 2 parents were consistent in all environments for all traits except plant height, days to heading, and tiller number. OUH602 was taller than Harrington in all test environments except F03SP, where Harrington was slightly taller than OUH602. Days to heading of the 2 parents were variable among the 4 test locations. Compared with Harrington, OUH602 headed earlier in F02IT but later in G03SP and at about the same time in F02SP and F03SP. Tiller number in OUH602 was less than that in Harrington in F03SP but slightly greater in F02IT and G03SP.

\section{QTL analysis of morphological and agronomic traits}

\section{Height}

Five QTLs were found for plant height (Table 2), but none was detected consistently across the 4 test environments. The QTLs on chromosomes 1(7H) (BINs 6 and 7), $3(3 \mathrm{H})(\mathrm{BIN} 5)$, and $5(1 \mathrm{H})(\mathrm{BIN} 12)$ were detected only in Italy. Each QTL explained about $11 \%$ to $13 \%$ of the phenotypic variation, and about $30 \%$ of the phenotypic variation was explained by all 3 QTLs. The Hsp allele for these QTLs increased plant height. The QTLs on chromosome $2(2 \mathrm{H})$ (BIN 5 and BIN 12) were detected only in the greenhouse experiment and explained $16 \%$ and $13 \%$ of the phenotypic variation, respectively. Together, these 2 QTLs explained $25 \%$ of the phenotypic variation in the greenhouse. The Hsp allele for these QTLs decreased plant height (Table 2).

\section{Flag leaf width}

Three QTLs were found for flag leaf width. The QTL on chromosome 2(2H) (BIN 3) was consistently detected in all environments and explained $13 \%$ to $22 \%$ of the phenotypic variation. The QTL on chromosome 4(4H) (BIN 13) was identified in F02SP and F03SP and explained about 11\% and $21 \%$ of the phenotypic variation, respectively. The QTL on chromosome $7(5 \mathrm{H})$ (BIN 2) was detected in F03SP and G03SP and explained $16 \%$ and $9 \%$ of the phenotypic variation, respectively. About $24 \%-43 \%$ of the phenotypic variation was explained by the 2 or 3 QTLs detected in each environment. The Hsp alleles for the QTLs on chromosomes $2(2 \mathrm{H})$ and $7(5 \mathrm{H})$ decreased flag leaf width; however, the Hsp allele for the QTL on chromosome 4(4H) increased leaf width (Table 2). 
Table 1. Morphological traits of parents and lines from the Harrington (HRT) / OUH602 (OUH) $\mathrm{BC}_{2} \mathrm{~F}_{8}$ population.

\begin{tabular}{|c|c|c|c|c|c|c|c|c|}
\hline \multirow[b]{2}{*}{ Trait } & \multirow[b]{2}{*}{ Environment $^{a}$} & \multicolumn{2}{|c|}{ Parents } & \multicolumn{3}{|c|}{ Population } & \multicolumn{2}{|l|}{$P$ value } \\
\hline & & HRT & $\mathrm{OUH}$ & Mean & Range & Error $\mathrm{MS}^{b}$ & Line & $\mathrm{E} \times \mathrm{L}^{c}$ \\
\hline \multirow{4}{*}{ Plant height $(\mathrm{cm})$} & F02IT & 98.2 & 113.8 & 100.3 & $89.3-115.2$ & 62.0 & $<0.0001$ & $<0.0001$ \\
\hline & F02SP & 62.8 & 67.8 & 64.5 & $54.2-76.8$ & 62.9 & $<0.0001$ & \\
\hline & F03SP & 63.7 & 62.5 & 65.2 & $45.3-83.5$ & 47.1 & $<0.0001$ & \\
\hline & G03SP & 89.4 & 96.6 & 95.2 & $65.1-112.8$ & 275.3 & $<0.0001$ & \\
\hline \multirow[t]{3}{*}{ Flag leaf width $(\mathrm{cm})$} & F02SP & 0.7 & 0.4 & 0.6 & $0.3-0.9$ & 0.1 & $<0.0001$ & $<0.0001$ \\
\hline & F03SP & 0.8 & 0.6 & 0.7 & $0.4-1.4$ & 0.1 & $<0.0001$ & \\
\hline & G03SP & 1.4 & 1.2 & 1.4 & $0.8-1.9$ & 0.1 & $<0.0001$ & \\
\hline \multirow[t]{4}{*}{ Spike length $(\mathrm{cm})$} & F02IT & 12.7 & 11.7 & 12.1 & $10.3-14.5$ & 2.2 & $<0.0001$ & $<0.0001$ \\
\hline & F02SP & 9.9 & 5.5 & 10.1 & $6.2-12.5$ & 5.2 & $<0.0001$ & \\
\hline & F03SP & 10.7 & 3.8 & 10.8 & $5.2-14.3$ & 3.2 & $<0.0001$ & \\
\hline & G03SP & 10.7 & 8.5 & 10.5 & $7.7-13.8$ & 220.7 & $<0.0001$ & \\
\hline \multirow[t]{3}{*}{ Spike width $(\mathrm{cm})$} & F02SP & 0.6 & 0.5 & 0.6 & $0.5-0.7$ & 0.01 & $<0.0001$ & $<0.0001$ \\
\hline & F03SP & 0.8 & 0.6 & 0.8 & $0.6-3.9$ & 0.08 & $<0.0001$ & \\
\hline & G03SP & 0.9 & 0.7 & 0.9 & $0.6-1.1$ & 234.3 & $<0.0001$ & \\
\hline \multirow[t]{2}{*}{ Glume length } & F03SP & 2.3 & 1.0 & 2.3 & $1.0-3.0$ & 0.6 & $<0.0001$ & 0.0099 \\
\hline & G03SP & 2.0 & 1.2 & 1.5 & $1.0-2.0$ & 232.2 & $<0.0001$ & \\
\hline \multirow[t]{4}{*}{ Awn length $(\mathrm{cm})$} & F02IT & 11.0 & 9.5 & 11.0 & $8.0-14.3$ & 3.9 & $<0.0001$ & $<0.0001$ \\
\hline & F02SP & 16.4 & 14.5 & 17.5 & $12.2-21.8$ & 9.9 & $<0.0001$ & \\
\hline & F03SP & 12.6 & 11.9 & 12.4 & $8.7-16.2$ & 2.5 & $<0.0001$ & \\
\hline & G03SP & 13.7 & 8.2 & 13.3 & $10.1-17.5$ & 212.3 & $<0.0001$ & \\
\hline \multirow[t]{2}{*}{ Fragile rachis } & F02IT & 0 & 5 & 0.5 & $0-5$ & 4.7 & $<0.0001$ & $<0.0001$ \\
\hline & F03SP & 1 & 2 & 1.1 & $1-2$ & 0.2 & $<0.0001$ & \\
\hline \multirow[t]{2}{*}{ Endosperm width (mm) } & F01SP & 3.5 & 2.3 & 3.1 & $2.8-3.5$ & 0.08 & $<0.0001$ & $<0.0001$ \\
\hline & F03SP & 3.7 & 2.3 & 3.4 & $2.2-4.2$ & 0.23 & $<0.0001$ & \\
\hline \multirow[t]{2}{*}{ Lateral groove depth } & F01SP & 5 & 1 & 4.9 & $3.7-5.0$ & 0.7 & $<0.0001$ & $<0.0001$ \\
\hline & F03SP & 5 & 1.7 & 4.4 & $1-5$ & 1.8 & $<0.0001$ & \\
\hline \multirow[t]{4}{*}{ Days to heading } & F02IT & 122.8 & 117.0 & 121.2 & $115.7-125.0$ & 17.8 & $<0.0001$ & $<0.0001$ \\
\hline & F02SP & 61.0 & 60.5 & 63.1 & $57.0-68.0$ & 19.5 & $<0.0001$ & \\
\hline & F03SP & 62.7 & 63.2 & 61.4 & $53.0-65.5$ & 14.8 & $<0.0001$ & \\
\hline & G03SP & 60.0 & 80.5 & 54.4 & $33.7-70.7$ & 200.4 & $<0.0001$ & \\
\hline \multirow[t]{3}{*}{ Flag leaf length $(\mathrm{cm})$} & F02IT & 17.3 & 17.1 & 16.2 & $11.5-22.3$ & 13.6 & $<0.0001$ & $<0.0001$ \\
\hline & F03SP & 13.1 & 9.7 & 12.8 & $8.0-21.5$ & 5.7 & $<0.0001$ & \\
\hline & G03SP & 22.8 & 15.7 & 22.1 & $12.3-34.1$ & 39.8 & $<0.0001$ & \\
\hline \multirow[t]{3}{*}{ Tiller number } & F02IT & 3.7 & 3.8 & 3.9 & $2.2-4.8$ & 1.1 & $<0.0001$ & 0.0125 \\
\hline & F03SP & 17.3 & 10.2 & 17.6 & $7-40$ & 33.8 & $<0.0001$ & \\
\hline & G03SP & 20.4 & 21.8 & 22.0 & $8.3-32.5$ & 69.4 & $<0.0001$ & \\
\hline \multirow[t]{2}{*}{ Kernel color } & F01SP & 1 & 3 & 1.1 & $1-3$ & 0.8 & $<0.0001$ & 0.1086 \\
\hline & F03SP & 1 & 3 & 1.1 & $1-3$ & 0.2 & $<0.0001$ & \\
\hline
\end{tabular}

\section{Spike length}

Four QTLs for spike length were identified. The QTL on chromosome $6(6 \mathrm{H})$ (BINs 5 and 6) was detected in F02IT, F03SP, and G03SP and explained between $10 \%$ and $20 \%$ of the phenotypic variation. The QTL on chromosome $2(2 \mathrm{H})$ (BINs 3-5) was detected in F02SP and G03SP and accounted for $12 \%-13 \%$ of the phenotypic variation. The QTL on chromosome 1(7H) (BIN 7) was identified only in F02IT and accounted for $12 \%$ of the phenotypic variation. The QTL on chromosome 3(3H) (BIN 4) was identified only in F03SP and accounted for 19\% of the phenotypic variation. About $13 \%-31 \%$ of the phenotypic variation was explained by the 1 or 2 QTLs detected in each environment.
The $H s p$ alleles for the QTLs on chromosomes $2(2 \mathrm{H})$ and $3(3 \mathrm{H})$ decreased spike length, whereas the alleles for the QTLs on chromosomes $1(7 \mathrm{H})$ and $6(6 \mathrm{H})$ increased spike length (Table 2).

\section{Spike width}

Two QTLs for spike width were detected in 2 of 3 environments tested. The QTL on chromosome 2(2H) (BIN 5) was detected in F02SP, and the QTL on chromosome $6(6 \mathrm{H})$ (BIN 12) was detected in G03SP. Each QTL explained between $16 \%$ and $18 \%$ of the phenotypic variation. The $H s p$ alleles of the 2 QTLs slightly decreased spike width (Table 2). 
Table 2. Locations of QTLs for plant height, flag leaf width, spike length, spike width, glume length in relation to seed length, awn length, fragility of ear rachis, endosperm width, lateral groove depth, days to heading, flag leaf length, number of tillers per plant, and kernel color traits in the Harrington/OUH602 advanced backcross $\left(\mathrm{BC}_{2} \mathrm{~F}_{8}\right)$ population.

\begin{tabular}{|c|c|c|c|c|c|c|c|c|}
\hline Trait & Environment $^{a}$ & $\begin{array}{l}\text { Chromosome } \\
\text { in } \text { RIL }^{b}\end{array}$ & Est. BIN ${ }^{c}$ & $\begin{array}{l}\text { Associated } \\
\text { marker(s) }\end{array}$ & LOD & $\alpha^{d}$ & $\operatorname{pr}(F)^{e}$ & $R^{2 f}$ \\
\hline \multirow[t]{5}{*}{ Plant height } & F02IT & $1(7 \mathrm{H})$ & $6-7$ & GBM1069 & 3.32 & 2.70 & $<0.0001$ & 13.67 \\
\hline & F02IT & $3(3 \mathrm{H})$ & 5 & Bmag0318a & 3.08 & 2.69 & $<0.0001$ & 12.66 \\
\hline & F02IT & $5(1 \mathrm{H})$ & 12 & GBM1002 & 2.82 & 2.56 & $<0.0001$ & $\begin{array}{l}11.20 \\
30.29^{g}\end{array}$ \\
\hline & G03SP & $2(2 \mathrm{H})$ & 5 & GBM1066a & 3.96 & -6.67 & $<0.0001$ & 16.11 \\
\hline & G03SP & $2(2 \mathrm{H})$ & 12 & HVM54 & 2.65 & -5.34 & 0.001 & $\begin{array}{l}13.39 \\
24.79^{g}\end{array}$ \\
\hline \multirow[t]{7}{*}{ Flag leaf width } & F02SP & $2(2 \mathrm{H})$ & 3 & HVM36 & 5.27 & -0.10 & $<0.0001$ & 21.68 \\
\hline & F02SP & $4(4 \mathrm{H})$ & 13 & Bmag0138.2 & 2.62 & 0.08 & 0.001 & $\begin{array}{l}10.64 \\
29.55^{g}\end{array}$ \\
\hline & F03SP & $2(2 \mathrm{H})$ & 3 & HVM36 & 3.32 & -0.08 & $<0.0001$ & 12.78 \\
\hline & F03SP & $4(4 \mathrm{H})$ & 13 & Bmag0138.2 & 5.60 & 0.10 & $<0.0001$ & 20.84 \\
\hline & F03SP & $7(5 \mathrm{H})$ & 2 & UMB705 & 3.78 & -0.08 & $<0.0001$ & $\begin{array}{l}16.26 \\
42.98^{g}\end{array}$ \\
\hline & G03SP & $2(2 \mathrm{H})$ & 3 & HVM36 & 4.40 & -0.14 & $<0.0001$ & 16.63 \\
\hline & G03SP & $7(5 \mathrm{H})$ & 2 & UMB705 & 2.30 & -0.11 & 0.001 & $\begin{array}{c}9.28 \\
24.11^{g}\end{array}$ \\
\hline \multirow[t]{7}{*}{ Spike length } & F02IT & $1(7 \mathrm{H})$ & 7 & GBM1069 & 2.99 & 0.52 & $<0.0001$ & 12.29 \\
\hline & F02IT & $6(6 \mathrm{H})$ & $5-6$ & GBM1027 & 4.27 & 0.68 & $<0.0001$ & $\begin{array}{l}16.13 \\
21.81^{g}\end{array}$ \\
\hline & F02SP & $2(2 \mathrm{H})$ & 5 & GBM1066a & 3.26 & -0.79 & $<0.0001$ & 13.28 \\
\hline & F03SP & $3(3 \mathrm{H})$ & 4 & Bmac0067 & 5.27 & -0.93 & $<0.0001$ & 19.25 \\
\hline & F03SP & $6(6 \mathrm{H})$ & 6 & Bmag0496 & 3.64 & 0.83 & $<0.0001$ & $\begin{array}{l}10.36 \\
31.04^{g}\end{array}$ \\
\hline & G03SP & $2(2 \mathrm{H})$ & 3 & HVM36 & 2.76 & -0.67 & $<0.0001$ & 12.40 \\
\hline & G03SP & $6(6 \mathrm{H})$ & $5-6$ & GBM1027 & 4.46 & 0.99 & $<0.0001$ & $\begin{array}{l}19.68 \\
27.15^{g}\end{array}$ \\
\hline \multirow[t]{2}{*}{ Spike width } & F02SP & $2(2 \mathrm{H})$ & 5 & GBM1066a & 4.51 & -0.04 & $<0.0001$ & 18.24 \\
\hline & G03SP & $6(6 \mathrm{H})$ & 12 & Bmac0040 & 3.98 & -0.06 & $<0.0001$ & 16.17 \\
\hline \multirow[t]{2}{*}{ Awn length } & F02IT & $3(3 \mathrm{H})$ & 4 & Bmac0067 & 2.63 & -0.61 & 0.001 & 11.15 \\
\hline & F03SP & $3(3 \mathrm{H})$ & 4 & Bmag0006 & 3.69 & -0.65 & $<0.0001$ & 10.70 \\
\hline \multirow[t]{6}{*}{ Fragile rachis } & F02IT & $3(3 \mathrm{H})$ & 4 & Bmac0067 & 8.24 & 1.05 & $<0.0001$ & 27.77 \\
\hline & F02IT & $5(1 \mathrm{H})$ & 12 & GBM1002 & 14.23 & 1.36 & $<0.0001$ & 53.82 \\
\hline & F02IT & $7(5 \mathrm{H})$ & 6 & Bmag0812 & 4.94 & 0.88 & $<0.0001$ & $\begin{array}{l}17.01 \\
71.39^{g}\end{array}$ \\
\hline & F03SP & $3(3 \mathrm{H})$ & 4 & Bmac0067 & 13.93 & 0.31 & $<0.0001$ & 44.37 \\
\hline & F03SP & $5(1 \mathrm{H})$ & 12 & GBM1002 & 3.84 & 0.20 & $<0.0001$ & 8.88 \\
\hline & F03SP & $7(5 \mathrm{H})$ & 6 & Bmag0812 & 3.94 & 0.19 & $<0.0001$ & $\begin{array}{l}17.32 \\
51.41^{g}\end{array}$ \\
\hline Endosperm width & F03SP & $2(2 \mathrm{H})$ & 13 & GBM1047 & 2.79 & -0.20 & $<0.0001$ & 9.42 \\
\hline Lateral groove depth & F01SP & $1(7 \mathrm{H})$ & $10-11$ & UMB101 & 2.98 & -0.23 & $<0.0001$ & 12.33 \\
\hline \multirow[t]{5}{*}{ Days to heading } & F02IT & $2(2 \mathrm{H})$ & 7 & Bmag0518 & 12.61 & -2.23 & $<0.0001$ & 42.65 \\
\hline & F02SP & $2(2 \mathrm{H})$ & $3-5$ & HVM36 & 4.62 & -2.10 & $<0.0001$ & 17.53 \\
\hline & F02SP & $2(2 \mathrm{H})$ & 7 & Bmag0518 & 3.58 & -1.72 & $<0.0001$ & $\begin{array}{l}12.24 \\
37.11^{g}\end{array}$ \\
\hline & F03SP & $2(2 \mathrm{H})$ & $3-5$ & GBM1066a & 6.44 & -2.44 & $<0.0001$ & 24.57 \\
\hline & G03SP & $2(2 \mathrm{H})$ & $3-5$ & HVM36 & 8.00 & -6.56 & $<0.0001$ & 29.37 \\
\hline \multirow[t]{5}{*}{ Flag leaf length } & F02IT & $1(7 \mathrm{H})$ & 11 & UMB101 & 3.11 & 1.75 & $<0.0001$ & 12.98 \\
\hline & F02IT & $7(5 \mathrm{H})$ & $6-8$ & UMB702 & 2.90 & 1.21 & $<0.0001$ & $\begin{array}{l}12.14 \\
27.50^{g}\end{array}$ \\
\hline & F03SP & $3(3 \mathrm{H})$ & $5-6$ & Bmac0138.1 & 3.62 & 1.08 & $<0.0001$ & 14.95 \\
\hline & F03SP & $7(5 \mathrm{H})$ & $6-8$ & UMB702 & 3.88 & 1.07 & $<0.0001$ & $\begin{array}{l}15.81 \\
28.25^{g}\end{array}$ \\
\hline & G03SP & $7(5 \mathrm{H})$ & 6 & UMB702 & 2.95 & 2.03 & $<0.0001$ & 12.21 \\
\hline
\end{tabular}


Table 2 (concluded).

\begin{tabular}{|c|c|c|c|c|c|c|c|c|}
\hline Trait & Environment $^{a}$ & $\begin{array}{l}\text { Chromosome } \\
\text { in } \text { RIL }^{b}\end{array}$ & Est. BIN ${ }^{c}$ & $\begin{array}{l}\text { Associated } \\
\text { marker(s) }\end{array}$ & LOD & $\alpha^{d}$ & $\operatorname{pr}(F)^{e}$ & $R^{2 f}$ \\
\hline \multirow[t]{4}{*}{ Tiller number } & F02IT & $5(1 \mathrm{H})$ & 6 & Bmag0872 & 2.49 & -0.38 & 0.001 & 10.32 \\
\hline & F03SP & $5(1 \mathrm{H})$ & 8 & GBM1013 & 3.26 & -2.25 & $<0.0001$ & 12.90 \\
\hline & G03SP & $2(2 \mathrm{H})$ & 3 & GBM1035 & 4.16 & -3.09 & $<0.0001$ & 15.72 \\
\hline & G03SP & $6(6 \mathrm{H})$ & $10-11$ & GBM1022 & 3.34 & -2.69 & $<0.0001$ & $\begin{array}{l}15.26 \\
24.55^{g}\end{array}$ \\
\hline \multirow[t]{2}{*}{ Kernel color } & F01SP and F03SP & $3(3 \mathrm{H})$ & $1-3$ & HvLTPPB & 2.86 & 0.21 & $<0.0001$ & 13.12 \\
\hline & F01SP and F03SP & $5(1 \mathrm{H})$ & $14-15$ & GBM1061 & 7.08 & 0.32 & $<0.0001$ & $\begin{array}{l}30.41 \\
34.86^{g}\end{array}$ \\
\hline
\end{tabular}

${ }^{a}$ The traits were evaluated in field experiments (F) in Cadriano, Italy (IT), in 2002, and in St. Paul, Minnesota (SP), in 2001, 2002, and 2003. The greenhouse experiment (G) was completed in winter 2003 in St. Paul.

${ }^{b}$ Map locations of markers in the Hsp OUH602/Harrington RIL population (Yun et al. 2005).

${ }^{c}$ Estimated BIN based on the chromosome BIN location of barley markers (http://barleygenomics.wsu.edu/).

${ }^{d}$ Average effect of substituting Harrington allele with OUH602 allele.

${ }^{e}$ Probability of $F$ statistics.

${ }^{f} R^{2} \times 100$, based on simple linear regression.

${ }^{g}$ Multiple regression model.

\section{Glume length}

No QTLs for glume length were identified.

\section{Awn length}

One QTL controlling awn length was detected on chromosome 3(3H) (BIN 4) in F02IT and F03SP and explained about $11 \%$ of the phenotypic variation in both environments. The Hsp allele of the QTL decreased awn length (Table 2).

\section{Fragility of ear rachis}

Three QTLs were identified in the 2 environments where the trait was evaluated. The QTL on chromosome $3(3 \mathrm{H})$ (BIN 4) explained $28 \%$ to $44 \%$ of the phenotypic variation. The QTL on chromosome 5(1H) (BIN 12) explained between $9 \%$ and $54 \%$ of the phenotypic variation. The QTL on chromosome $7(5 \mathrm{H})$ (BIN 6) explained $17 \%$ of the phenotypic variation. Together, the 3 QTLs explained 51\%-71\% of the phenotypic variation in each environment. The $H s p$ alleles for all the QTLs increased fragility of ear rachis (Table 2).

\section{Endosperm width}

One QTL on chromosome 2(2H) (BIN 13) was detected for endosperm width only in F03SP, and it explained 9\% of the phenotypic variation. The Hsp allele for the QTL decreased endosperm width (Table 2).

\section{Lateral seed groove depth}

A QTL for seed groove depth was identified in F01SP on chromosome $1(7 \mathrm{H})$ (BINs 10 and 11 ), and it explained $12 \%$ of the phenotypic variation. The Hsp allele for the QTL decreased the score of seed groove depth by changing the seed groove to Hsp type (Table 2).

\section{Days to heading}

Two QTLs for days to heading were identified. The QTL on chromosome 2(2H) (BINs 3-5) was identified in F02SP, F03SP, and G03SP and explained 18\% to $29 \%$ of the phenotypic variation. The QTL on chromosome $2(2 \mathrm{H})$ (BIN 7) was mapped in F02IT and F02SP and accounted for 12\% to $43 \%$ of the phenotypic variation. About $25 \%-43 \%$ of the phenotypic variation was explained by the 1 or 2 QTLs detected in each environment. The $H s p$ alleles for each QTL decreased days to heading (Table 2).

\section{Flag leaf length}

Three QTLs for flag leaf length were identified. The QTL on chromosome $7(5 \mathrm{H})$ (BINs 6-8) was consistently identified in all 3 environments where this trait was measured. This QTL explained between $12 \%$ and $16 \%$ of the phenotypic variation. The QTL on chromosome 1(7H) (BIN 11) was identified only in F02IT, and the QTL on chromosome $3(3 \mathrm{H})$ (BINs 5 and 6) was found only in F03SP. The QTLs on chromosomes $1(7 \mathrm{H})$ and $3(3 \mathrm{H})$ explained $13 \%$ and $15 \%$ of the phenotypic variation, respectively. About 12\%-28\% of the phenotypic variation was explained by the 1 or 2 QTLs detected in each environment. The Hsp alleles for each QTL increased flag leaf length (Table 2).

\section{Tiller number}

Three QTLs for tiller number were identified. The QTL on chromosome $5(1 \mathrm{H})$ (BINs 6-8) was detected in 2 locations and explained about $10 \%-13 \%$ of the phenotypic variation. Two additional QTLs were identified on chromosomes $2(2 \mathrm{H})(\mathrm{BIN} 3)$ and $6(6 \mathrm{H})(\mathrm{BINs} 10$ and 11) and they accounted for $16 \%$ and $15 \%$ of the phenotypic variation, respectively. About $10 \%-25 \%$ of the phenotypic variation was explained by the 1 or 2 QTLs detected in each environment. The $H s p$ alleles for the QTL decreased tiller number (Table 2).

\section{Kernel color}

Two QTLs for kernel color were identified on chromosomes 3(3H) (BINs 1-3) and 5(1H) (BINs 14 and 15) and explained $13 \%$ and $30 \%$ of the phenotypic variation, respectively. Together, the 2 QTLs explained 35\% of the phenotypic variation. The $H s p$ alleles for the QTLs resulted in darker kernel color (Table 2).

\section{Discussion}

Modern barley cultivars are easily distinguished from the 
wild progenitor $H s p$ by contrasting phenotypes for a variety of morphological and agronomic traits. In this study, we examined the genetic architecture underlying the phenotypic differences for 13 morphological and agronomic traits and identified 30 QTLs. The location and number of QTLs associated with these traits were determined in an $\mathrm{AB}$ population derived from the cross between the Hsp accession OUH602 and the 2-rowed barley cultivar Harrington. The results from this study provide a framework for understanding the genetic differences controlling morphological and agronomic traits between wild and cultivated barley.

\section{Novel loci for many morphological and agronomic traits were identified}

Sixteen of the 30 identified QTLs for the 13 morphological traits investigated were newly identified in this study (Fig. 1). Four of these newly described QTLs were identified in 2 environments and 3 were found in 3 environments. All QTLs identified for plant height were reported previously (Hayes et al. 1993; Qi et al. 1998; Borem et al. 1999; de la Peña et al. 1999; Marquez-Cedillo et al. 2001). The QTLs for spike length on chromosomes 2(2H) (BINs 3-5) and 1(7H) (BIN 7) (Kjaer et al. 1995; Hori et al. 2005) are consistent with the previously reported regions, but the other QTLs for spike length on chromosomes $3(3 \mathrm{H})$ (BIN 4) and $6(6 \mathrm{H})$ (BINs 5 and 6$)$ are newly identified regions. The QTL for fragile rachis on chromosome $3(3 \mathrm{H})$ (BIN 4) corresponds to the loci for the complementary genes Btrl and Btr2 (Takahashi and Hayashi 1964; Larson et al. 1996; Kandemir et al. 2000, 2004; Komatsuda et al. 2004). The QTL on chromosome $7(5 \mathrm{H})(\mathrm{BIN} 6)$ for fragile rachis might correspond to the previously identified QTL on chromosome $7(5 \mathrm{H})$ (BIN 8) (von Korff et al. 2006). However, the QTL found in our study for fragile rachis on chromosome $5(1 \mathrm{H})$ (BIN 12) is a newly identified locus. The heading date QTLs in BINs 3-5 of chromosome 2(2H) (Hayes et al. 1993; Backes et al. 1995; Kjaer et al. 1995; Powell et al. 1997; Qi et al. 1998; von Korff et al. 2004) and in BIN 7 of chromosome 2(2H) (Kjaer et al. 1995; Tinker et al. 1996; de la Peña et al. 1999; Marquez-Cedillo et al. 2001; Mesfin et al. 2003) were identified previously. The tiller number QTLs on chromosomes $2(2 \mathrm{H})(\mathrm{BIN} 3)$ and $5(1 \mathrm{H})(\mathrm{BINs} 6-8)$ might correspond to the regions reported earlier (Baum et al. 2003), but the QTL on chromosome 6(6H) (BINs 10 and 11) is unique to this work. The kernel color QTL on chromosome $5(1 \mathrm{H})$ (BINs 14 and 15) is coincident with a locus for black lemma (Franckowiak 1997); however, the QTL on chromosome $3(3 \mathrm{H})$ (BINs 1-3) is novel to this work. Additionally, all QTLs associated with flag leaf width, flag leaf length, spike width, awn length, endosperm width, and lateral groove depth are novel to this work.

\section{Utility of QTLs detected in this study}

The AB-QTL method was developed to identify potentially useful genes in wild relatives that were left behind during domestication and breeding (Tanksley and Nelson 1996). The accession used in this study, OUH602, has been found to be a source of novel resistance genes for Septoria speckled leaf blotch (Yun et al. 2005). Hori et al. (2005) described OUH602 (referred to as H602) as carrying positive alleles at QTLs for spike length, culm length, number of spikelets, and heading date. The mere detection of positive alleles from the wild parent does not necessarily mean that those alleles will be useful in plant breeding. The value of an allele from a wild accession is dependent on the cultivated genetic background used in the study. In addition, many QTLs discovered in wild by cultivated crosses are coincident with QTLs identified in standard mapping studies of cultivated barley. In these cases, if the coincident QTLs represent the same gene, then the wild allele may be the same as or similar to alleles already present in cultivated barley. At this time, we do not know whether the alleles identified in our study that control differences between wild and cultivated barley will provide a practical benefit for breeding. The additional effort necessary to introgress genes free of linkage drag from wild species, even with the use of markers, is great enough to warrant careful consideration of potentially useful alleles from wild parents.

\section{OUH602 mapping in different populations and environments}

The Hsp accession OUH602 has been used to identify QTLs in other genetic backgrounds (Hori et al. 2005) and in our study in the different environments of Minnesota and Italy. Hori et al. (2005) used populations of recombinant chromosome substitution and doubled haploid lines derived from OUH602 crossed to Haruna Nijo to identify QTLs controlling culm length, ear length, number of spikelets, glume length, rachis-internode length, thousand kernel mass, heading date, and seed dormancy. The ear length and heading date traits were also examined in our study. We mapped a QTL for spike length (ear length) on chromosomes $7 \mathrm{H}$ (BIN 7), 6(6H) (BINs 5 and 6), 2(2H) (BINs 3-5), and $3(3 \mathrm{H})(\mathrm{BIN} 4)$, and Hori et al. (2005) mapped this trait on chromosome $2(2 \mathrm{H})$ in BINs 3-5. We mapped a QTL for heading date on chromosome $2(2 \mathrm{H})$ (BINs 2, 3, and 7), whereas Hori et al. (2005) mapped a QTL for heading date on chromosome $4(4 \mathrm{H})$. Thus, for the 2 traits we can directly compare, our results are consistent for only the 1 QTL controlling spike length on chromosome $2(2 \mathrm{H})$. In addition, we observed differences in QTL detection between the Minnesota and Italian environments. For example, we detected a QTL for spike length on chromosome 1(7H) in the Italian environment that was not detected in the Minnesota environments. These differences are likely due to the spring and winter growing conditions in Minnesota and Italy, respectively. These comparisons illustrate the problems of identifying all QTLs for a particular trait based on a single population examined in a few environments. A single population restricts the number of segregating alleles and few environments will limit the phenotypic variation that could be observed in different environments.

\section{Genetic architecture of morphological and agronomic traits in a wild by cultivated barley population}

The results from this study provide the opportunity to examine the genetic architecture of morphological and agronomic traits in a wild by cultivated population. We observed 1 to 4 QTLs for each of the traits except glume length. The portion of phenotypic variation explained by individual QTLs ranged from $9 \%$ to $54 \%$, and most of the individual QTLs explained 9\% to $25 \%$ of the phenotypic 
Fig. 1. Locations of quantitative trait loci (QTLs) for morphological traits. Chromosomes were scaled as in the linkage map generated from the OUH602 $\times$ Harrington RIL population (Yun et al. 2005). QTLs at chromosomal regions similar to those of previously reported QTLs are underlined. Locations of the known QTLs were adopted from the Barley World Web site (http://www.barleyworld.org). Letters in parentheses correspond to previously described QTL locations that are coincident with those reported in this paper: $a$, Backes et al. 1995; $b$, Baum et al. 2003; $c$, Borem et al. 1999; $d$, de la Peña et al. 1999; $e$, Hayes et al. 1993; $f$, Hori et al. 2005; $g$, Kandemir et al. 2000; $h$, Kandemir et al. 2004; $i$, Kjaer et al. 1995; $j$, Komatsuda et al. 2004; $k$, Marquez-Cedillo et al. 2001; $l$, Powell et al. 1997; $m$, Qi et al. 1998; $n$, von Korff et al. 2006; $o$, Franckowiak et al. 1997. Abbreviations used are as follows: AL, awn length; DH, days to heading; EW, endosperm width; LW, flag leaf width; LL, flag leaf length; FR, fragility of ear rachis; GR, lateral groove depth; PH, plant height; SL, spike length; SW, spike width; TN, tiller number; KC, kernel color. Numbers after the trait abbreviations are chromosome BIN numbers.

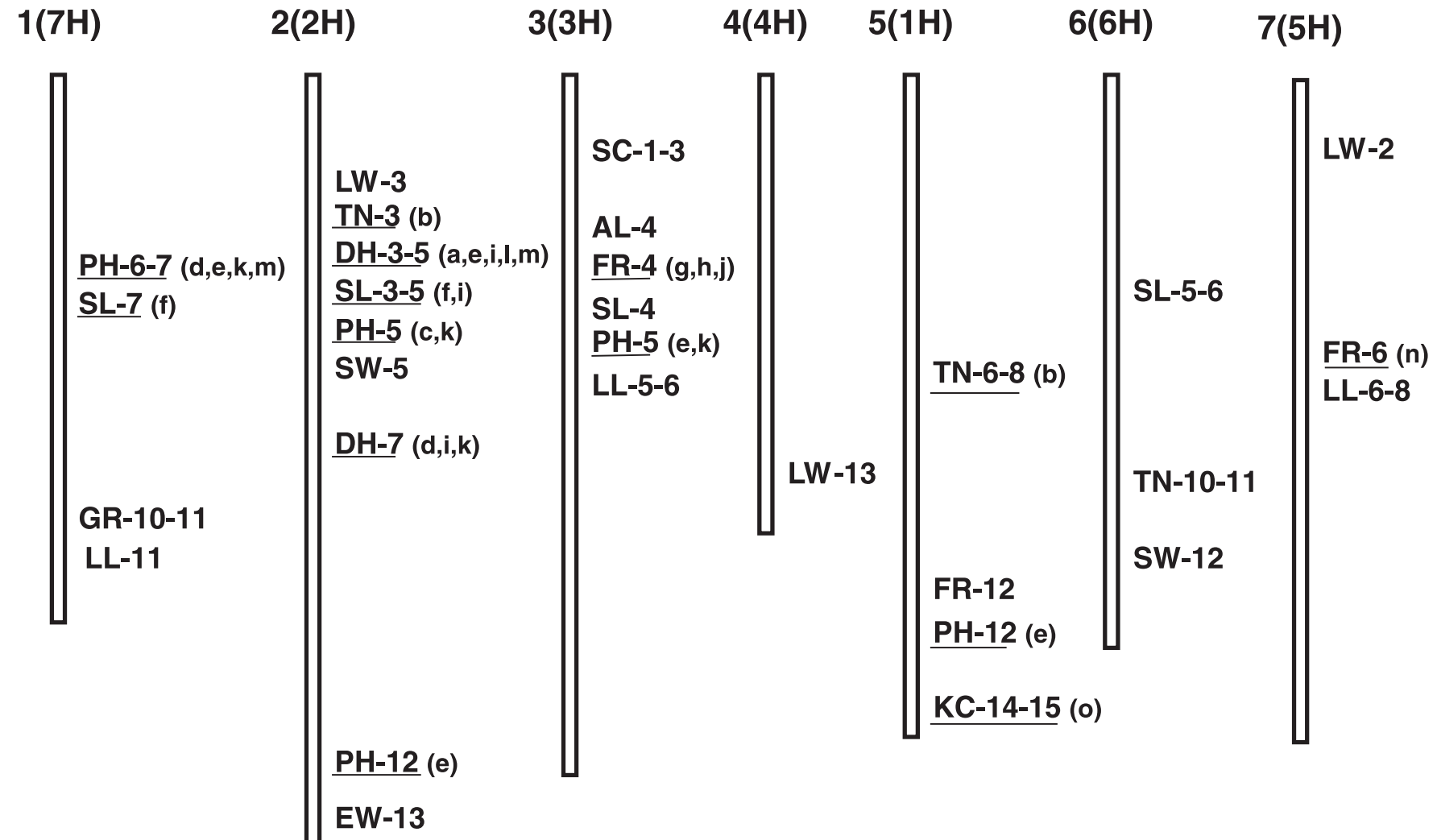

variation. For the most part, the multiple QTL model for any particular trait explained only a small portion $(<35 \%)$ of the phenotypic variation. One noteworthy exception was fragile rachis: 3 QTLs together explained over 50\% of the variation in 2 environments. We also observed that 11 QTLs were clustered in 2 regions on chromosome 2(2H) (BINs 3-5) and chromosome 3 (BINs 4-6), with 6 and 5 QTLs in each region, respectively. Both related and non-related traits were linked in the clustered regions. For example, QTLs for spike length and width, days to heading, plant height, flag leaf width, and tiller number were found on chromosome $2(2 \mathrm{H})$ (BINs 3-5) and QTLs for spike length, awn length, fragile rachis, plant height, and flag leaf length were found on chromosome $3(3 \mathrm{H})$ (BINs 4-6). These results seem to suggest that loci controlling morphological and agronomic traits are clustered in a few regions of the genome. However, size characters such as plant height and spike length are likely traits that exhibit pleiotropic effects. Moreover, drawing conclusions about the number and effects of QTLs based on relatively small mapping populations must be done with caution. In general, population sizes similar to the one used in this study will underestimate the number of QTLs controlling a trait and overestimate the importance of those QTLs detected (Melchinger et al. 1998; Utz et al. 2000). Given these statistical limitations, and the fact that only 1 population in a limited number of environments was examined, we cannot conclude that these traits in barley are controlled by a few clustered loci. Nevertheless, our analysis establishes the positions of the QTLs for these traits on the barley genetic map.

To further define the molecular architecture of morphological and agronomic traits that differentiate wild and cultivated barley, additional wild by cultivated populations evaluated in multiple environments are required. As described above, different populations having OUH602 as the wild parent and characterized in different environments resulted in identification of different QTLs. Moreover, characterization of wild and cultivated germplasm collections using association genetics approaches will also help elucidate the genomic structure of these traits. 


\section{Acknowledgements}

We thank the Institute of Plant Genetics, Gatersleben, Germany, for providing us with the GBM series of SSR markers. This work was supported by grants from the North America Barley Genome Project to G.J.M., B.J.S., and K.P.S. S.J.Y. was supported by grants from Chonbuk National University and BioGreen 21 Program, Rural Development Administration, Republic of Korea. E.B. was supported by a grant from the University of Bologna.

\section{References}

Backes, G., Graner, A., Forought-Wehr, B., Fischbeck, G., Wenzel, G., and Jahoor, A. 1995. Localization of quantitative trait loci (QTL) for agronomic important characters by use of RFLP map in barley (Hordeum vulgare L.). Theor. Appl. Genet. 90: 294302. doi:10.1007/BF00222217.

Badr, A., Müller, K., Schäfer-Pregl, R., El Rabey, H., Effgen, S., Ibrahim, H.H., et al. 2000. On the origin and domestication history of barley (Hordeum vulgare). Mol. Biol. Evol. 17: 499-510. PMID:10742042.

Baum, M., Grando, S., Backes, G., Jahoor, A., Sabbagh, A., and Ceccarelli, S. 2003. QTLs for agronomic traits in the Mediterranean environment identified in recombinant inbred lines of the cross 'Arta' $\times$ H. spontaneum 41-1. Theor. Appl. Genet. 107: 1215-1225. doi:10.1007/s00122-003-1357-2. PMID:12898030.

Borem, A., Mather, D.E., Rasmusson, D.C., Fulcher, R.G., and Hayes, P.M. 1999. Mapping quantitative trait loci for starch granule traits in barley. J. Cereal Sci. 29: 153-160. doi:10.1006/ jcrs.1998.0217.

de la Peña, R., Smith, K.P., Capettini, F., Muehlbauer, G.J., GalloMeagher, M., Dill-Macky, R., Somers, D.A., and Rasmusson, D.C. 1999. Quantitative trait loci associated with resistance to Fusarium head blight and kernel discoloration in barley. Theor. Appl. Genet. 99: 561-569. doi:10.1007/s001220051269.

Eshed, Y., and Zamir, D. 1995. An introgression line population of Lycopersicon pennellii in the cultivated tomato enables the identification and fine mapping of yield-associated QTL. Genetics, 141: 1147-1162. PMID:8582620.

Franckowiak, J. 1997. Revised linkage maps for morphological markers in barley, Hordeum vulgare. Barley Genet. Newsl. 26: 9-21.

Fulton, T.M., Grandillo, S., Beck-Bunn, T., Fridman, E., Frampton, A., Lopez, J., et al. 2000. Advanced backcross QTL analysis of a Lycopersicon esculentum $\times$ Lycopersicon parviflorum cross. Theor. Appl. Genet. 100: 1025-1042. doi:10.1007/ s001220051384.

Hayes, P.M., Liu, B.H., Knapp, S.J., Chen, F., Jones, B., Blake, T., et al. 1993. Quantitative trait locus effects and environmental interaction in a sample of North American barley germplasm. Theor. Appl. Genet. 87: 392-401. doi:10.1007/BF01184929.

Hori, K., Sato, K., Nankaku, N., and Takeda, K. 2005. QTL analysis in recombinant chromosome substitution lines and doubled haploid lines derived from a cross between Hordeum vulgare ssp. vulgare and Hordeum vulgare ssp. spontaneum. Mol. Breed. 16: 295-311. doi:10.1007/s11032-005-0998-z.

Kandemir, N., Kudrna, D.A., Ullrich, S.E., and Kleinhofs, A. 2000. Molecular marker assisted genetic analysis of head shattering in six-rowed barley. Theor. Appl. Genet. 101: 203-210. doi:10. 1007/s001220051470.

Kandemir, N., Yildirim, A., Kudrna, D.A., Hayes, P.M., and Kleinhofs, A. 2004. Marker assisted genetic analysis of non-brittle rachis trait in barley. Hereditas, 141: 272-277. doi:10.1111/j. 1601-5223.2004.01841.x. PMID:15703043.
Kjaer, B., Jensen, J., and Giese, H. 1995. Quantitative trait loci for heading date and straw characters in barley. Genome, 38: 10981104.

Komatsuda, T., Maxim, P., Senthil, N., and Mano, Y. 2004. Highdensity AFLP map of nonbrittle rachis 1 (btrl) and 2 (btr2) genes in barley (Hordeum vulgare L.). Theor. Appl. Genet. 109: 986-995. doi:10.1007/s00122-004-1710-0. PMID:15490100.

Larson, S.R., Kadyrzhanova, D., McDonald, C., Sorrells, M., and Blake, T.K. 1996. Evaluation of barley chromosome-3 yield QTLs in a backcross $\mathrm{F}_{2}$ population using STS-PCR. Theor. Appl. Genet. 93: 618-625.

Li, J.Z., Huang, X.Q., Heinrichs, F., and Ganal, M.W. 2005. Analysis of QTLs for yield, yield components, and malting quality in a $\mathrm{BC}_{3}-\mathrm{DH}$ population of spring barley. Theor. Appl. Genet. 110: 356-363. doi:10.1007/s00122-004-1847-x. PMID: 15549229 .

Li, J.Z., Huang, X.Q., Ganal, M.W., and Röder, M.S. 2006. Analysis of QTLs for yield components, agronomic traits, and disease resistance in an advanced backcross population of spring barley. Genome, 49: 454-466. doi:10.1139/G05-128. PMID:16767170.

Marquez-Cedillo, L.A., Hayes, P.M., Kleinhofs, A., Legge, W.G., Rossnagel, B.G., Sato, K., Ullrich, S.E., and Wesenberg, D.M. 2001. QTL analysis of agronomic traits in barley based on the doubled haploid progeny of two elite North American varieties representing different germplasm groups. Theor. Appl. Genet. 103: 625-637. doi:10.1007/PL00002919.

Melchinger, A.E., Utz, H.F., and Schoen, C.C. 1998. Quantitative trait locus (QTL) mapping using different testers and independent population samples in maize reveals low power of QTL detection and large bias in estimates of QTL effects. Genetics, 149: 383-403. PMID:9584111.

Mesfin, A., Smith, K.P., Dill-Macky, R., Evans, C.K., Waugh, R., Gustus, C.D., and Muehlbauer, G.J. 2003. Quantitative trait loci for Fusarium head blight resistance in barley in a two-rowed by six-rowed population. Crop Sci. 43: 307-318.

Nevo, E. 1992. Origin, evolution, population genetics and resources for breeding of wild barley, Hordeum spontaneum, in the Fertile Crescent. In Barley: genetics, biochemistry, molecular biology and biotechnology. Edited by Peter Shewry. CAB International Press, London. pp. 19-43.

Pillen, K., Zacharias, A., and Léon, J. 2004. Comparative AB-QTL analysis in barley using a single exotic donor of Hordeum vulgare ssp. spontaneum. Theor. Appl. Genet. 108: 1591-1601. doi:10.1007/s00122-004-1586-z. PMID:14968306.

Powell, W., Thomas, W.T.B., Baird, E., Lawrence, P., Booth, A., Harrower, B., McNicol, J.W., and Waugh, R. 1997. Analysis of quantitative traits in barley by the use of amplified fragment length polymorphisms. Heredity, 79: 48-59. doi:10.1038/sj.hdy. 6881820.

Qi, X., Nicks, E.E., Stam, P., and Lindhourt, P. 1998. Identification of QTLs for partial resistance to leaf rust (Puccinia hordei) in barley. Theor. Appl. Genet. 96: 1205-1213. doi:10.1007/ s001220050858.

Sato, K., and Takeda, K. 1997. Net blotch resistance in wild species of Hordeum. Euphytica, 95: 179-185. doi:10.1023/ A:1002958924439.

Takahashi, R., and Hayashi, J. 1964. Linkage study of two complementary genes for brittle rachis in barley. Ber. Ohara Inst. Landwirtsch. Biol. Okayama Univ. 12: 99-105.

Talamè, V., Sanguineti, M.C., Chiapparino, E., Bahri, H., Ben Salem, M., Forster, B.P., et al. 2004. Identification of Hordeum spontaneum QTL alleles improving field performance of barley grown under rainfed conditions. Ann. Appl. Biol. 144: 309-319. doi:10.1111/j.1744-7348.2004.tb00346.x. 
Tanksley, S.D., and Nelson, J.C. 1996. Advanced backcross QTL analysis: a method for the simultaneous discovery and transfer of valuable QTLs from unadapted germplasm into elite breeding lines. Theor. Appl. Genet. 92: 191-203. doi:10.1007/ s001220050114.

Tinker, N.A., Mather, D.E., Rossnagel, B.G., Kasha, K.J., Kleinhofs, A., Hayes, P.M., et al. 1996. Regions of the genome that affect agronomic performance in two-row barley. Crop Sci. 36: 1053-1062.

Utz, H.F., Melchinger, A.E., and Schön, C.C. 2000. Bias and sampling error of the estimated proportion of genotypic variance explained by quantitative trait loci determined from experimental data in maize using cross validation and validation with independent samples. Genetics, 154: 1839-1849. PMID:10866652.

von Korff, M., Wang, H., Léon, J., and Pillen, K. 2004. Development of candidate introgression lines using an exotic barley accession (Hordeum vulgare ssp. spontaneum) as donor. Theor. Appl. Genet. 109: 1736-1745. doi:10.1007/s00122-004-1818-2. PMID:15502912.

von Korff, M., Wang, H., Léon, J., and Pillen, K. 2006. AB-QTL analysis in spring barley: II. Detection of favourable exotic alleles for agronomic traits introgressed from wild barley $(H . v u l-$ gare ssp. spontaneum). Theor. Appl. Genet. 112: 1221-1231. doi:10.1007/s00122-006-0223-4. PMID:16477429.
Wang, S., Basten, C.J., Gaffney, P., and Zeng, Z.B. 2005. Windows QTL Cartographer v2.5 [online]. Bioinformatics Research Center, North Carolina State University, Raleigh, N.C. Available from http://statgen.ncsu.edu/qtlcart/ [cited 3 August 2007].

Xiao, J., Grandillo, S., Ahn, S.N., McCouch, S.R., Tanksley, S.D., Li, J., and Yuan, L. 1996. Genes from wild rice improve yield. Nature (London), 384: 223-224. doi:10.1038/384223a0.

Yun, S.J., Gyenis, L., Hayes, P.M., Matus, I., Smith, K.P., Steffenson, B.J., and Muehlbauer, G.J. 2005. Identification of quantitative trait loci for multiple disease resistance in wild barley. Crop Sci. 45: 2563-2572. doi:10.2135/cropsci2005.0236.

Yun, S.J., Gyenis, L., Hayes, P.M., Matus, I., Smith, K.P., Steffenson, B.J., et al. 2006. Validation of quantitative trait loci for multiple disease resistance using advanced backcross lines developed with a wild barley accession (Hordeum vulgare ssp. spontaneum). Crop Sci. 46: 1179-1186. doi:10.2135/cropsci2005.08-0293.

Zhu, H., Gilchrist, L., Hayes, P., Kleinhofs, A., Kudrna, D., Lui, Z., et al. 1999. Does function follow form? QTLs for Fusarium head blight (FHB) resistance are coincident with QTLs for inflorescence traits and plant height in a doubled haploid population of barley. Theor. Appl. Genet. 99: 1221-1232. doi:10.1007/ s001220051328. 